\title{
Relationship Between CHADS2 Score and Efficacy of Antiarrhythmic Drug Therapy in Patients With Paroxysmal Atrial Fibrillation
}

Takashi Komatsu, MD; Yoshihiro Sato, MD; Mahito Ozawa, MD; Fusanori Kunugita, MD; Hironobu Ueda, MD; Hideaki Tachibana, MD; Yoshihiro Morino, MD; Motoyuki Nakamura, MD

\begin{abstract}
Background: The Cardiac failure, Hypertension, Age, Diabetes, Stroke [Doubled] (CHADS 2 ) score is a useful scheme for risk stratification of thromboembolism patients, but there is little information about its usefulness for the evaluation of antiarrhythmic drug (AAD) therapy.
\end{abstract}

Methods and Results: This study included 459 paroxysmal atrial fibrillation (AF) patients (309 men, mean age $66 \pm 12$ years, mean follow-up 50 \pm 35 months) and prophylactic efficacy was analyzed on the basis of CHADS 2 score. (1) Survival rates free from AF recurrence at 1, 6, 12 and 24 months were, respectively, 89\%, 74\%, 63\% and 47\% in score-0 group $(n=152) ; 92 \%, 68 \%, 59 \%$ and $48 \%$ in score- 1 group $(n=158) ; 86 \%, 64 \%, 56 \%$ and $46 \%$ in score-2 group ( $n=84) ; 81 \%, 65 \%, 51 \%$ and $35 \%$ in score-3 group $(n=43)$; and $68 \%, 50 \%, 36 \%$ and $18 \%$ in $\geq$ score- 4 group $(n=22)(P<0.05$; score-0, score-1 or score-2 vs. $\geq$ score-4 group). (2) Survival rates free from progression to chronic AF at 12, 36, 60 and 90 months were, respectively, 95\%, 93\%, 91\% and $89 \%$ in score-0 group; $97 \%, 91 \%, 89 \%$ and $88 \%$ in score-1 group; $96 \%, 93 \%, 88 \%$ and $83 \%$ in score-2 group; $91 \%, 74 \%, 67 \%$ and $60 \%$ in score-3 group; and $91 \%, 82 \%, 68 \%$ and $55 \%$ in $\geq$ score-4 group ( $\mathrm{P}<0.01$; score- 0 , score- 1 or score- 2 vs. $\geq$ score- 4 group). (3) In multivariate logistic regression analysis adjusted for potentially confounding variables, CHADS 2 score was associated with $A F$ recurrence (odds ratio $[\mathrm{OR}] 1.45,95 \%$ confidence interval $[\mathrm{Cl}] 1.16-1.81, \mathrm{P}<0.001$ ), and progression to chronic AF during AAD therapy (OR 1.64, 95\% Cl 1.04-2.69, $\mathrm{P}<0.001$ ).

Conclusions: When using a rhythm control strategy, the $\mathrm{CHADS}_{2}$ score is a useful scheme for predicting the outcome of AAD treatment of patients with paroxysmal AF. (Circ $J$ 2013; 77: 639-645)

Key Words: Antiarrhythmic drugs; Atrial fibrillation; $\mathrm{CHADS}_{2}$ score; Prevention; Prognosis

$\mathbf{E}$ pidemiological studies in Europe and the United States indicate that the prevalence of atrial fibrillation $(\mathrm{AF})$ increases substantially with age to approximately $4 \%$ in people in their $70 \mathrm{~s}$ and approximately $10 \%$ in people in their 80 s. $^{1}$ In Japan, where the elderly population is increasing rapidly, the prevalence of AF is also high, at approximately $1 \%$ among people in their $60 \mathrm{~s}$ and $2-3 \%$ among those in their $70 \mathrm{~s}$, and it is expected that the prevalence of $\mathrm{AF}$ will reach 1,000 per 100,000 population in $2010-2030,{ }^{2}$ and further increase in the future. AF is thus considered an important condition that will significantly affect the healthcare system in Japan and other developed countries.

Because AF often causes cardiovascular complications such as thromboembolism and heart failure ${ }^{3}$ and deteriorates prognosis, especially in patients with left ventricular (LV) dysfunction, ${ }^{4}$ patients with AF should be properly treated and man- aged. The prognosis of patients with cardiogenic ischemic stroke is poorer than those with atherosclerotic cerebral infarction, and it is reported that cardiogenic stroke recurs within 1 year in approximately $40 \%$ of patients who do not receive appropriate anticoagulation therapy. ${ }^{5}$ In the Guidelines for the Management of Patients with Atrial Fibrillation proposed by the American College of Cardiology, the American Heart Association and the European Society of Cardiology in 2006, stroke risk in patients with nonvalvular AF is stratified according to the Cardiac failure, Hypertension, Age, Diabetes, Stroke [Doubled] (CHADS 2 ) score, and antithrombotic therapy for patient with AF is recommended for each risk category. ${ }^{6}$ However, few studies have investigated the relationship between the long-term preventive efficacy of recurrent AF by antiarrhythmic drugs (AAD) used to maintain sinus rhythm in patients with paroxysmal $\mathrm{AF}$ and the $\mathrm{CHADS}_{2}$ score.

Received July 10, 2012; revised manuscript received October 1, 2012; accepted October 30, 2012; released online December 5, 2012 Time for primary review: 16 days

Division of Cardio-angiology, Nephrology and Endocrinology (T.K., Y.S., M.O., F.K., H.U., H.T., M.N.), Division of Cardiology (Y.M.), Department of Internal Medicine, Iwate Medical University, Morioka, Japan

Mailing address: Takashi Komatsu, MD, Division of Cardioangiology, Nephrology and Endocrinology, Department of Internal Medicine, Iwate Medical University, 19-1 Uchimaru, Morioka 020-8505, Japan. E-mail: sym.koma@imu.ncvc.go.jp

ISSN-1346-9843 doi:10.1253/circj.CJ-12-0854

All rights are reserved to the Japanese Circulation Society. For permissions, please e-mail: cj@j-circ.or.jp 


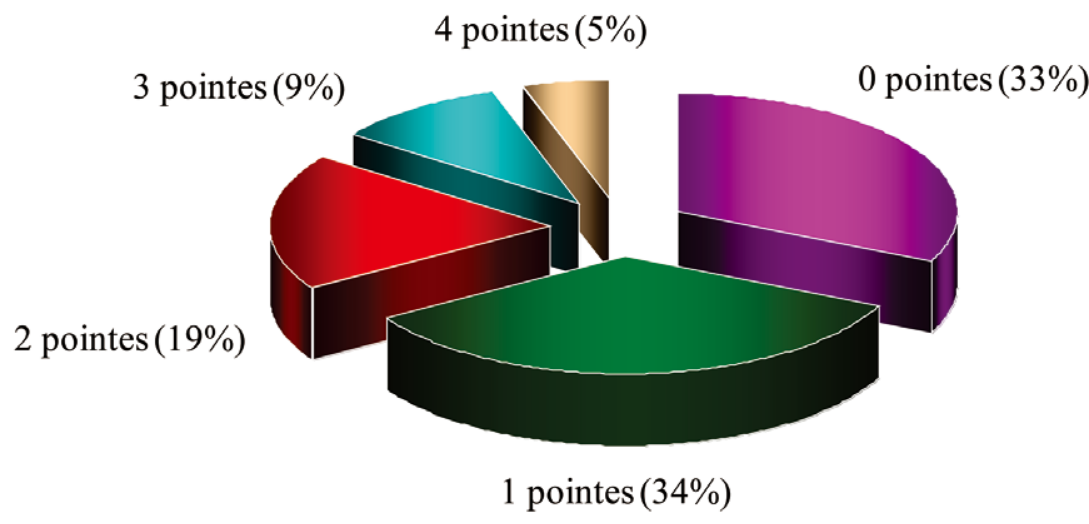

Figure 1. Distribution of $\mathrm{CHADS}_{2}$ scores in patients with paroxysmal atrial fibrillation.

\section{Methods}

\section{Study Participants}

A total of 459 consecutive patients (309 males, 150 females) with symptomatic paroxysmal AF detected using the standard 12-lead ECG and ambulatory 24-h ECG participated in the study. The mean age was $66 \pm 12$ years, and the mean $\mathrm{CHADS}_{2}$ score was $1.2 \pm 1.1$. Participants had to visit the clinic every 2-4 weeks, undergo rhythm control therapy using AAD, and be under observation for more than 1 year. All patients were screened for diabetes mellitus using fasting glucose and hemoglobin Alc levels. All patients also underwent medical interview, chest X-ray, exercise tolerance test and echocardiography or other appropriate noninvasive examination for underlying cardiopulmonary diseases, and the investigators performed pulmonary function test, chest $\mathrm{CT}$ and cardiac catheterization whenever necessary.

Patients with congestive heart failure; serious bradyarrhythmia (eg, sick sinus syndrome, atrioventricular block, bifascicular block or more); thyroid, hepatic or renal dysfunction; or a history of drug allergy and women of child-bearing potential during the study period were excluded. The study was conducted between June 1997 and October 2010, and the mean observation period was 50 \pm 35 months (range 12-127 months).

\section{Definitions}

Paroxysmal AF was defined as episodes that terminate spontaneously within 7 days. ${ }^{7}$ Permanent (chronic) AF was defined as long-standing AF in which pharmacologic agents and/or electrical cardioversion had failed to maintain sinus rhythm for at least 6 months. Cerebral thromboembolism was diagnosed from the occurrence of typical clinical signs/symptoms and the presence of infarction $\geq 3 \mathrm{~mm}$ in diameter detected by CT or MRI. Hypertension was defined according to the guidelines proposed by the Japanese Society of Hypertension in $2009,{ }^{8}$ and hyperlipidemia was defined as a fasting serum cholesterol $\geq 220 \mathrm{mg} / \mathrm{dl}$ and triglycerides $\geq 150 \mathrm{mg} / \mathrm{dl} .{ }^{9}$ Chronic obstructive pulmonary disease was defined as a forced expiratory volume in $1 \mathrm{~s}$ percent $\left(\mathrm{FEV}_{1.0}\right) \leq 70 \%$. AF was classified by time of onset into diurnal type (episodes occurring during the day, from 7:00 to 17:00 hours), nocturnal type (episodes occurring at night, from 17:00 to 7:00 hours), and mixed type (within 24 hours in both day and night). ${ }^{10}$ Recurrence of AF was defined as the first ECG-documented AF episode during treatment with antiarrhythmic treatment.

\section{Protocol for AAD Therapy}

All patients received rhythm control therapy to maintain sinus rhythm. For AF patients who had $\geq 40 \%$ LV ejection fraction (LVEF) revealed by transthoracic echocardiography, Class I AAD were administered at the discretion of outpatient physicians after spontaneous or electrical cardioversion to sinus rhythm. When AF recurred during treatment with more than 1 Class I AAD, patients who provided informed consent for more aggressive treatment received amiodarone at a dose of $200 \mathrm{mg} /$ day. For patients who did not give consent to receive amiodarone, their physicians prescribed Class I AAD other than those previously used.

Patients with LVEF $<40 \%$ were treated with aprindine $60 \mathrm{mg}$ /day or bepridil $150 \mathrm{mg}$ /day as a first- or second-line therapy after spontaneous or electric cardioversion. Patients in whom AF recurred during treatment with either of these 2 drugs received amiodarone $200 \mathrm{mg}$ /day as third-line therapy.

At 2-4 weeks after the initiation or modification of AAD treatment, the patients were interviewed for subjective symptoms of AF and underwent standard 12-lead ECG and simple ambulatory ECG monitoring. When considered necessary by the attending physicians, patients underwent 24-h ambulatory ECG monitoring every 3 months to evaluate for recurrent AF.

Patients with chronic AF despite full AAD therapy were treated orally with $\beta$-blockers, calcium-cancel blockers or digitalis to control the ventricular heart rate.

\section{Protocol of Antithrombotic Therapy}

Before the guidelines for drug treatment of arrhythmia were published by the Japanese Circulation Society (JCS) in November $2001,{ }^{11}$ physicians determined whether antithrombotic therapy was indicated and, if indicated, which type of treatment should be given. In November 2001 and thereafter, patients received antithrombotic therapy according to the JCS guidelines, and were treated with antithrombotic drugs when the physicians considered them necessary. During antithrombotic treatment, patients received aspirin at a dose of 81$100 \mathrm{mg} /$ day or warfarin according to the guidelines to achieve an INR of 1.6-3.0.

The $\mathrm{CHADS}_{2}$ score was calculated for each patient to evaluate the distribution of patients, patient characteristics and the efficacy of AAD treatment in preventing recurrent $\mathrm{AF}$ and chronic $\mathrm{AF}$ on the basis of $\mathrm{CHADS}_{2}$ score. The patients were also stratified by the efficacy of AAD therapy to specify predictive factors for recurrent and chronic AF. 
Table 1. Patients' Characteristics and First-Line Therapy on the Basis of CHADS 2 Score

\begin{tabular}{|c|c|c|c|c|c|c|}
\hline \multirow[b]{3}{*}{ A. Patients' characteristics } & \multicolumn{5}{|c|}{ CHADS $_{2}$ score } & \multirow{2}{*}{$P$ value } \\
\hline & \multirow[t]{2}{*}{0} & \multirow[t]{2}{*}{1} & \multirow[t]{2}{*}{2} & \multirow[t]{2}{*}{3} & \multirow[t]{2}{*}{$4 \leq$} & \\
\hline & & & & & & \\
\hline $\mathrm{n}$ & 152 & 158 & 84 & 43 & 22 & \\
\hline Observation period (months) & $45 \pm 33$ & $49 \pm 36$ & $56 \pm 40$ & $58 \pm 33$ & $54 \pm 30$ & NS \\
\hline Age (years) & $58 \pm 12$ & $67 \pm 10$ & $72 \pm 9$ & $72 \pm 9$ & $78 \pm 7$ & $<0.001$ \\
\hline $\operatorname{Sex}(M / F)$ & $110 / 42$ & $100 / 58$ & $53 / 31$ & $30 / 13$ & $16 / 6$ & NS \\
\hline Hypertension & $0(0 \%)$ & $105(66 \%)$ & $57(68 \%)$ & $26(60 \%)$ & $16(73 \%)$ & $<0.001$ \\
\hline Diabetes mellitus & $0(0 \%)$ & $16(10 \%)$ & $25(30 \%)$ & $14(33 \%)$ & $5(23 \%)$ & $<0.001$ \\
\hline Dyslipidemia & $20(13 \%)$ & $21(13 \%)$ & $12(14 \%)$ & $5(12 \%)$ & $2(9 \%)$ & NS \\
\hline Smoking & $47(31 \%)$ & $31(20 \%)$ & $21(25 \%)$ & $13(30 \%)$ & $2(9 \%)$ & NS \\
\hline Alcohol & 79 (52\%) & $55(35 \%)$ & $26(31 \%)$ & $16(37 \%)$ & $6(27 \%)$ & NS \\
\hline Hyperuricemia & $6(4 \%)$ & $12(8 \%)$ & 7 (8\%) & $2(5 \%)$ & $2(9 \%)$ & NS \\
\hline Underlying heart disease & $34(22 \%)$ & $45(28 \%)$ & $35(42 \%)$ & $10(23 \%)$ & $6(27 \%)$ & NS \\
\hline Underlying pulmonary disease & $6(4 \%)$ & $6(4 \%)$ & $3(4 \%)$ & $4(9 \%)$ & $1(5 \%)$ & NS \\
\hline Asymptomatic AF & $9(6 \%)$ & $18(11 \%)$ & $9(11 \%)$ & $9(21 \%)$ & $4(18 \%)$ & NS \\
\hline \multicolumn{7}{|l|}{ B. Patients' characteristics } \\
\hline $\mathrm{n}$ & 152 & 158 & 84 & 43 & 22 & \\
\hline AF history (months) & $17 \pm 31$ & $20 \pm 52$ & $19 \pm 32$ & $19 \pm 44$ & $14 \pm 17$ & NS \\
\hline LVDd (mm) & $45.4 \pm 5.4$ & $45.9 \pm 5.5$ & $46.3 \pm 6.2$ & $45.6 \pm 5.6$ & $47.1 \pm 3.9$ & NS \\
\hline $\operatorname{LAd}(\mathrm{mm})$ & $33.9 \pm 7.0$ & $36.5 \pm 6.9$ & $36.8 \pm 7.7$ & $36.1 \pm 6.27$ & $37.2 \pm 5.4$ & $<0.001$ \\
\hline LVEF (\%) & $68.9 \pm 10.1$ & $67.0 \pm 10.9$ & $66.6 \pm 12.0$ & $69.0 \pm 10.9$ & $63.6 \pm 11.6$ & NS \\
\hline RAAS inhibitors & $14(9 \%)$ & $59(37 \%)$ & $40(48 \%)$ & $15(35 \%)$ & $8(36 \%)$ & NS \\
\hline Statin & $20(13 \%)$ & $22(14 \%)$ & $13(15 \%)$ & $5(12 \%)$ & $2(9 \%)$ & NS \\
\hline \multicolumn{7}{|l|}{ Antithrombotic therapy } \\
\hline None & $83(55 \%)$ & $75(47 \%)$ & $30(36 \%)$ & $17(40 \%)$ & $10(45 \%)$ & NS \\
\hline Aspirin & $28(18 \%)$ & $49(31 \%)$ & $22(26 \%)$ & $13(30 \%)$ & $2(10 \%)$ & NS \\
\hline Warfarin & $41(27 \%)$ & $34(22 \%)$ & $32(38 \%)$ & $13(30 \%)$ & $10(45 \%)$ & NS \\
\hline \multicolumn{7}{|l|}{ At registration } \\
\hline ANP during SR (pg/ml) & $34.5 \pm 38.1$ & $46.6 \pm 48.9$ & $50.0 \pm 48.2$ & $40.4 \pm 27.6$ & $38.5 \pm 27.8$ & NS \\
\hline \multicolumn{7}{|l|}{ Onset of AF } \\
\hline Diurnal:nocturnal:mixed & 19:67:66 & $35: 52: 71$ & $17: 18: 49$ & $8: 07: 28$ & 3:05:14 & NS \\
\hline \multicolumn{7}{|l|}{ C. Patients' characteristics } \\
\hline $\mathrm{OMI}$ & $5(15 \%)$ & $6(13 \%)$ & $7(20 \%)$ & $4(40 \%)$ & $1(17 \%)$ & NS \\
\hline Angina pectoris & $6(18 \%)$ & $12(27 \%)$ & $7(20 \%)$ & $0(0 \%)$ & $1(17 \%)$ & NS \\
\hline $\mathrm{DCM}$ & $4(12 \%)$ & $5(11 \%)$ & $5(14 \%)$ & $1(10 \%)$ & $1(17 \%)$ & NS \\
\hline $\mathrm{HCM}$ & $5(15 \%)$ & $5(16 \%)$ & $4(11 \%)$ & $2(20 \%)$ & $1(17 \%)$ & NS \\
\hline Valvular disease & $8(24 \%)$ & $9(20 \%)$ & $10(29 \%)$ & $1(10 \%)$ & 2 (32\%) & NS \\
\hline Myocarditis & $1(3 \%)$ & $0(0 \%)$ & $0(0 \%)$ & $0(0 \%)$ & $0(0 \%)$ & NS \\
\hline Syndrome X & $1(3 \%)$ & $0(0 \%)$ & $0(0 \%)$ & $0(0 \%)$ & $0(0 \%)$ & NS \\
\hline ASD & $2(6 \%)$ & $3(7 \%)$ & $1(3 \%)$ & $0(0 \%)$ & $0(0 \%)$ & NS \\
\hline Tetralogy of Fallot & $0(0 \%)$ & $1(2 \%)$ & $0(0 \%)$ & $0(0 \%)$ & $0(0 \%)$ & NS \\
\hline SSS & $2(6 \%)$ & $2(4 \%)$ & $1(3 \%)$ & $2(20 \%)$ & $0(0 \%)$ & NS \\
\hline \multicolumn{7}{|l|}{ D. First-line therapy } \\
\hline Disopyramide & $32(21 \%)$ & $35(22 \%)$ & $18(21 \%)$ & $7(16 \%)$ & 7 (32\%) & NS \\
\hline Aprindine & $21(14 \%)$ & $18(11 \%)$ & $18(21 \%)$ & $8(19 \%)$ & $3(14 \%)$ & NS \\
\hline Cibenzoline & $46(30 \%)$ & $50(32 \%)$ & $24(29 \%)$ & $8(19 \%)$ & $5(23 \%)$ & NS \\
\hline Pilsicainide & $19(13 \%)$ & $22(14 \%)$ & $9(11 \%)$ & $9(21 \%)$ & $4(18 \%)$ & NS \\
\hline Flecainide & $12(8 \%)$ & $8(5 \%)$ & $4(5 \%)$ & $4(9 \%)$ & $1(5 \%)$ & NS \\
\hline Propafenone & $3(2 \%)$ & $1(1 \%)$ & $1(1 \%)$ & $2(5 \%)$ & $0(0 \%)$ & NS \\
\hline Pirmenol & $7(5 \%)$ & $6(4 \%)$ & $0(0 \%)$ & $1(2 \%)$ & $0(0 \%)$ & NS \\
\hline Bepridil & $6(4 \%)$ & $11(7 \%)$ & $4(5 \%)$ & $2(5 \%)$ & $2(9 \%)$ & NS \\
\hline Amiodarone & $5(3 \%)$ & $6(4 \%)$ & $3(4 \%)$ & $2(5 \%)$ & $0(0 \%)$ & NS \\
\hline Verapamil & $1(1 \%)$ & $1(1 \%)$ & $1(1 \%)$ & $0(0 \%)$ & $0(0 \%)$ & NS \\
\hline$\beta$-blockers & $0(0 \%)$ & $0(0 \%)$ & $2(2 \%)$ & $0(0 \%)$ & $0(0 \%)$ & NS \\
\hline
\end{tabular}

AF, atrial fibrillation; ANP, atrial natriuretic peptide; ASD, atrial septal defect; $\mathrm{CHADS}_{2}$, Cardiac failure, Hypertension, Age, Diabetes, Stroke [Doubled] score; HCM, hypertrophic cardiomyopathy; LAd, left atrial dimension; LVDd, left ventricular end-diastolic dimension; LVEF, left ventricular ejection fraction; OMI, old myocardial infarction; RAAS, renin-angiotensin-aldosterone system; SR, sinus rhythm; SSS, sick sinus syndrome. 


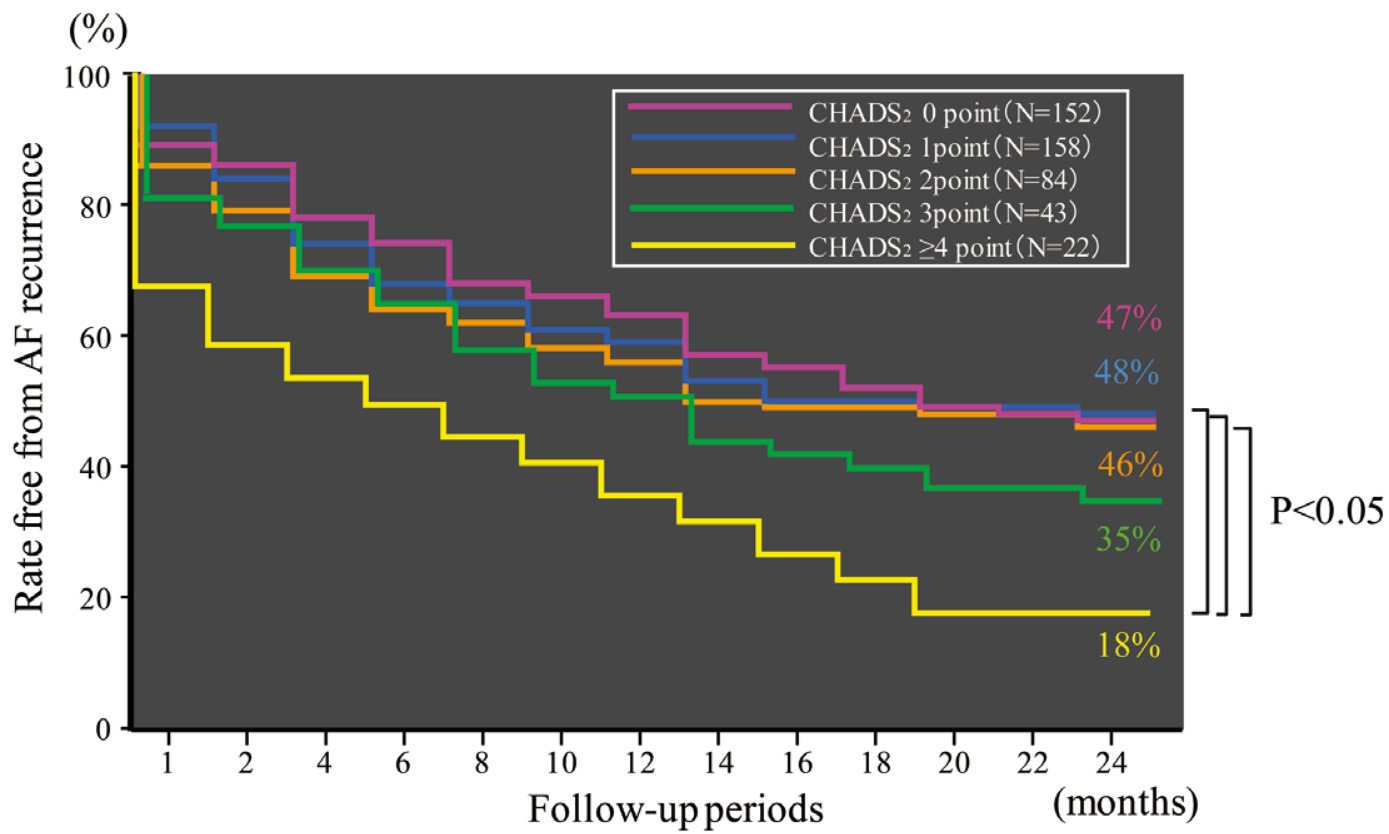

Figure 2. Survival curve free from atrial fibrillation recurrence on the basis of $\mathrm{CHADS}_{2}$ score.

\begin{tabular}{lcc|}
\hline $\begin{array}{l}\text { Table 2. Predictors of Recurrent AF During Antiarrhythmic } \\
\text { Drug Therapy* }\end{array}$ & OR (95\% Cl) & P value \\
Mixed type (onset of AF) & $6.081(3.857-9.586)$ & 0.001 \\
CHADS score & $1.766(1.140-2.737)$ & 0.011 \\
Statins & $1.845(0.966-3.525)$ & 0.063 \\
Hypertension & $0.612(0.341-1.099)$ & 0.100 \\
AF history (months) & $1.005(0.999-1.011)$ & 0.119 \\
Diabetes mellitus & $0.586(0.268-1.283)$ & 0.182 \\
Non-ischemic heart disease & $0.621(0.300-1.287)$ & 0.200 \\
Sex (male) & $1.367(0.845-2.211)$ & 0.203 \\
RAAS inhibitors & $0.716(0.422-1.213)$ & 0.214 \\
LVDd (mm) & $0.974(0.934-1.016)$ & 0.219 \\
Valvular heart disease & $1.857(0.616-5.601)$ & 0.272 \\
Age (years) & $0.994(0.973-1.015)$ & 0.567 \\
Cardiac failure & $1.366(0.448-4.168)$ & 0.583 \\
Ischemic heart disease & $0.870(0.420-1.801)$ & 0.707 \\
LVEF (\%) & $1.003(0.981-1.026)$ & 0.763 \\
LAd (mm) & $0.995(0.964-1.027)$ & 0.774 \\
Past history of cerebral infarction & $0.881(0.300-2.586)$ & 0.881 \\
\hline
\end{tabular}

*Multivariate logistic regression analysis.

$\mathrm{Cl}$, confidence interval; OR, odds ratio. Other abbreviations as in Table 1.

\section{Statistical Analysis}

The obtained values were expressed as mean and standard deviation. Patient characteristics were compared between subgroups by use of the Mann-Whitney U test, and patient percentages were compared with the chi-square test. The percentage of patients without ischemic stroke was evaluated using the Kaplan-Meier method, and differences between subgroups were tested for significance using the log-rank test. Multivariate logistic analysis was used to identify predictive factors for ischemic stroke and cardiovascular accidents, and the HosmerLemeshow goodness-of-fit test was used to validate the model. All statistical analyses were performed using the SPSS 13.0 statistical package (Chicago, IL, USA). A P-value $<0.05$ was considered statistically significant.

\section{Results}

\section{Distribution of CHADS2 Score in Patients With Paroxysmal AF}

In the 459 patients evaluated in the study, the $\mathrm{CHADS}_{2}$ score was 0 in 152 patients (33\%), 1 in 158 patients (34\%), 2 in 84 patients (19\%), 3 in 43 patients $(9 \%)$ and $\geq 4$ in 22 patients (5\%) (Figure 1).

\section{Comparison of Patient Characteristics on the Basis of CHADS2 Score (Table 1)}

Although significant differences in age and the prevalence of hypertension and diabetes and left atrial diameter (LAd) were observed among subgroups stratified by $\mathrm{CHADS}_{2}$ score $(\mathrm{P}<0.01)$, no differences on the basis of $\mathrm{CHADS}_{2}$ score were observed in other factors evaluated.

\section{Survival Curve Free From AF Recurrence on the Basis of CHADS2 Score}

The percentages of patients without recurrent AF (AF recurrence-free rate) at months $1,6,12$ and 24 of follow-up were, respectively, $89 \%, 74 \%, 63 \%$ and $47 \%$ in the patients with a $\mathrm{CHADS}_{2}$ score of $0(\mathrm{n}=152) ; 92 \%, 68 \%, 59 \%$ and $48 \%$ in the patients with a $\mathrm{CHADS}_{2}$ score of $1(\mathrm{n}=158) ; 86 \%, 64 \%, 56 \%$ and $46 \%$ in the patients with a $\mathrm{CHADS}_{2}$ score of $2(\mathrm{n}=48)$; $81 \%, 65 \%, 51 \%$ and $35 \%$ in the patients with a CHADS 2 score of $3(n=43)$; and $68 \%, 50 \%, 36 \%$, and $18 \%$ in the patients with 


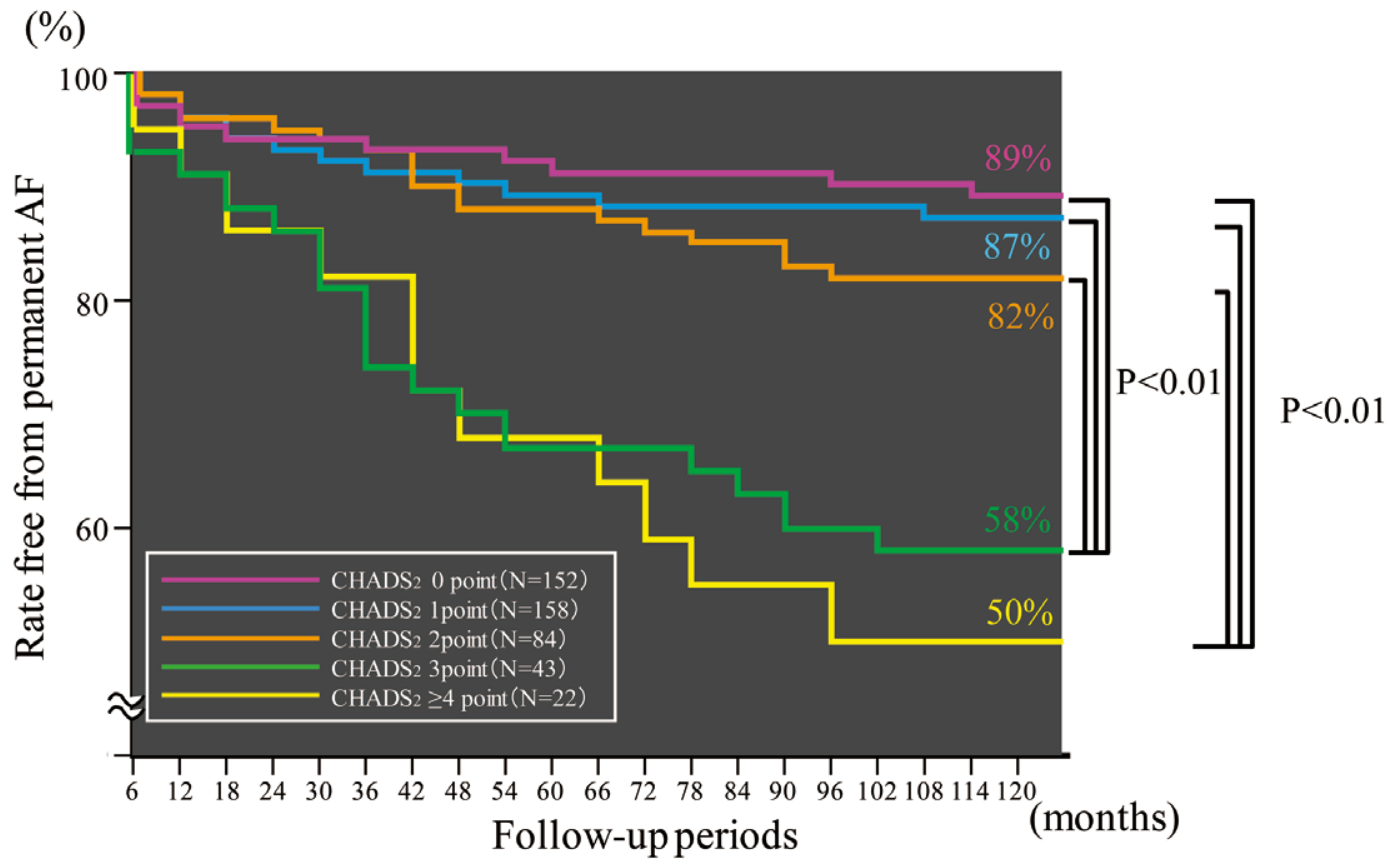

Figure 3. Survival curve free from progression to chronic atrial fibrillation on the basis of CHADS2 score.

a $\mathrm{CHADS}_{2}$ score $\geq 4(\mathrm{n}=22)$. The survival rate free from $\mathrm{AF}$ recurrence at month 24 of follow-up was significantly higher in patients with a CHADS 2 score of 0,1 or 2 than in those with score $\geq 4(\mathrm{P}<0.05)$ (Figure 2$)$.

\section{Predictors for Recurrent AF During AAD Therapy}

Multivariate analysis adjusted for potentially confounding variables evaluated in the study revealed that mixed type $\mathrm{AF}$ [odds ratio (OR) 6.20, 95\% confidence interval (CI) 3.96-9.70, $\mathrm{P}=0.001]$ and $\mathrm{CHADS}_{2}$ score $(\mathrm{OR} 1.45,95 \% \mathrm{CI} 1.18-1.87$; $\mathrm{P}=0.002$ ) were independent predictors for recurrent $\mathrm{AF}$ during AAD therapy (Table 2).

\section{Survival Curve Free From Progression to Chronic AF on the Basis of CHADS 2 Score}

The percentages of patients without chronic AF (chronic AFfree rate) at months 12, 36, 60, 90 and 120 of follow-up were, respectively, $95 \%, 93 \%, 91 \%, 91 \%$ and $89 \%$ in the patients with $\mathrm{CHADS}_{2}$ score $0 ; 97 \%, 91 \%, 89 \%, 88 \%$ and $87 \%$ in the patients with $\mathrm{CHADS}_{2}$ score 1; 96\%, 93\%, 88\%, 83\% and $82 \%$ in the patients with $\mathrm{CHADS}_{2}$ score $2 ; 91 \%, 74 \%, 67 \%$, $60 \%$, and $58 \%$ in the patients with $\mathrm{CHADS}_{2}$ score 3 ; and $91 \%$, $82 \%, 68 \%, 55 \%$ and $50 \%$ in the patients with $\mathrm{CHADS}_{2}$ score 4 or 5 . The survival rate free from progression to chronic $\mathrm{AF}$ at month 120 of follow-up was significantly higher in the patients with $\mathrm{CHADS}_{2}$ score 0,1 or 2 than in those with $\mathrm{CHADS}_{2}$ score 4 or $5(\mathrm{P}<0.01)$ (Figure 3$)$.

Predictors for Progression to Chronic AF During AAD Therapy Multivariate analysis adjusted for potentially confounding variables evaluated in the study revealed that mixed type AF [OR $16.43,95 \%$ CI $1.02-263.8, \mathrm{P}=0.001], \mathrm{CHADS}_{2}$ score (OR $1.64,95 \%$ CI 1.01-2.69; $\mathrm{P}=0.001)$, AF history (OR 1.01, 95\% CI 1.00-1.13; $\mathrm{P}=0.002)$ and LAd (OR 1.053 ; 95\% CI 1.00

\begin{tabular}{|lcc|}
\hline \multicolumn{3}{|c|}{$\begin{array}{c}\text { Table 3. Predictors of Progression to Chronic AF During } \\
\text { Antiarrhythmic Drug Therapy* }\end{array}$} \\
Mixed type (onset of AF) & $18.57(7.394-46.66)$ & 0.001 \\
AF history (months) & $1.012(1.004-1.020)$ & 0.004 \\
LAd (mm) & $1.067(1.019-1.116)$ & 0.005 \\
CHADS 2 score & $2.198(1.246-3.880)$ & 0.007 \\
Hypertension & $0.469(0.215-1.023)$ & 0.057 \\
RAAS inhibitors & $0.202(0.037-1.099)$ & 0.064 \\
Ischemic heart disease & $0.513(0.246-1.070)$ & 0.075 \\
Cardiac failure & $2.356(0.800-6.933)$ & 0.120 \\
LVDd (mm) & $1.041(0.982-1.104)$ & 0.177 \\
LVEF (\%) & $1.032(0.963-1.061)$ & 0.399 \\
Valvular heart disease & $1.541(0.550-4.316)$ & 0.410 \\
Statins & $0.459(0.204-1.998)$ & 0.452 \\
Age (years) & $1.013(0.978-1.048)$ & 0.476 \\
Sex (male) & $1.252(0.619-2.532)$ & 0.531 \\
Past history of cerebral infarction & $0.698(0.201-2.429)$ & 0.572 \\
Non-ischemic heart disease & $1.232(0.480-3.160)$ & 0.664 \\
Diabetes mellitus & $0.926(0.357-2.401)$ & 0.874 \\
\hline
\end{tabular}

${ }^{*}$ Multivariate logistic regression analysis.

Abbreviations as in Tables 1,2.

1.03; $\mathrm{P}=0.019)$ were independent predictors for chronic $\mathrm{AF}$ during AAD therapy (Table 3).

\section{Discussion}

\section{Main Results of the Study}

In the present study, $\mathrm{CHADS}_{2}$, which is a risk stratification 
score for thromboembolism, was identified as an independent predictor for recurrent and progression to chronic AF in patients with paroxysmal AF during AAD therapy to maintain sinus rhythm.

\section{Significance of CHADS2 Score in Patients With AF}

It has been reported that prior ischemic stroke, age, hypertension, diabetes and heart failure are independently associated with increased risk of cardiogenic cerebral embolism in patients with nonvalvular AF. ${ }^{12}$ The $\mathrm{CHADS}_{2}$ score was developed on the basis of these findings. In an epidemiological study of 1,733 patients aged 65-95 years with nonvalvular AF who were discharged from hospital without anticoagulation therapy, high $\mathrm{CHADS}_{2}$ scores were associated with increased age-adjusted incidence of stroke. ${ }^{13}$ The $\mathrm{CHADS}_{2}$ score has been reported as a useful tool in risk stratification for ischemic stroke in patients with nonvalvular paroxysmal AF in Japan, ${ }^{14}$ but as far as we know, there have been no studies of the relationship between $\mathrm{CHADS}_{2}$ score and efficacy of AAD therapy. Because most of the patients in the present study had normal or slightly impaired LVEF (Table 1B), Class I AAD were selected as the first-line therapy in approximately $90 \%$ of all patients with paroxysmal AF. However, it should be noted that aimless long-term treatment with Class I AAD may endanger the cardiovascular prognosis in patients with LV dysfunction, ${ }^{15}$ even if it is ideal for the maintenance of sinus rhythm. A previous report demonstrated the progressive nature of paroxysmal AF during long-term observation. ${ }^{16}$ In particular, the survival rate free from progression to chronic $\mathrm{AF}$ at months 60 and 90 of follow-up in the patients with $\mathrm{CHADS}_{2}$ score 3 or $\geq 4$ in the present study seems to be similar to that in the previous report. However, in the present study, a higher $\mathrm{CHADS}_{2}$ score was associated with poor efficacy of antiarrhythmic therapy in preventing AF. In the multivariate analysis adjusted for potentially confounding variables evaluated, $\mathrm{CHADS}_{2}$ score was an independent predictor for the efficacy of AAD therapy in preventing recurrent and chronic AF.

It has been pointed out that duration of AF episodes, ${ }^{17,18}$ medical history, ${ }^{19}$ increased LAd ${ }^{18}$ underlying heart disease, ${ }^{18,19}$ heart failure, ${ }^{18}$ age, ${ }^{20,21}$ and diabetes mellitus ${ }^{22}$ among others predict the efficacy of AAD therapy in patients with paroxysmal AF. The $\mathrm{CHADS}_{2}$ score includes age, heart failure and diabetes, which have been reported to affect the efficacy of AAD in preventing AF. The age-related increase in the prevalence of AF has been reported in epidemiological studies, ${ }^{1,2}$ and explained as being caused by the formation of an electrophysiological propensity to AF because of the increased incidence of age-related supraventricular extrasystole, ${ }^{23}$ as well as fibrosis or degeneration of atrial muscles. ${ }^{24}$ The Framingham Heart Study, ${ }^{25}$ a large-scale epidemiological survey in the United States, revealed that the risk of AF increases by a factor of 4.5-5.9 in patients with heart failure as compared with those without it, and it has been reported that AF develops in $10-30 \%$ of patients with decreased LV function, represented by $\mathrm{LVEF} \leq 40 \%$, and the incidence increases as the severity of heart failure increases. ${ }^{26}$ It also has been pointed out that volume and pressure overload related to heart failure activates the renin-angiotensin-aldosterone system (RAAS), hypertrophy and fibrosis of atrial muscles, and that calcium overload typical of heart failure may increase the dispersion of the atrial refractory period and cause supraventricular extrasystole. Patients with diabetes mellitus often have diffuse fibrosis of the cardiac interstitium and typical findings of myocardial degeneration with wall thickening and luminal narrowing because of the deposition of mucopolysaccharides in the intramyocar- dial coronary vessels. ${ }^{27}$ Also, prolonged hyperglycemia may activate the polyol pathway and decrease the activity of scavenging active oxygen species and hydrogen peroxide, which may eventually decrease the nerve conduction velocity. ${ }^{28} \mathrm{Be}$ cause many AAD act on particular membrane channels and receptors on the atrial myocytes, it is readily expected that the progression of deterioration and fibrosis of atrial muscles associated with diabetes may cause attenuation of the pharmacological effect of AAD on their targets. In the present study, mixed type AF, irrespective of circadian variation, was also a significant predictor for recurrent and progression to chronic AF during AAD therapy. The initiation of paroxysmal AF and clinical course refractory to AAD therapy may occur in mixed type AF that derives from fibrosis or degeneration of atrial muscles rather than from involvement of the autonomic nervous system.

In the Atrial Fibrillation Follow-up Investigation of Rhythm Management (AFFIRM) Study, a large-scale multinational study that compared 2 long-term treatment strategies for AF, sinus rhythm and anticoagulation therapy were independent predictors for cardiovascular prognosis in patients with AF. ${ }^{29}$ If the sinus rhythm maintenance rate is actually lower in patients with paroxysmal AF with cardiovascular risks and high $\mathrm{CHADS}_{2}$ score, as suggested in the present study, the cardiovascular prognosis of such patients is expected to be poor. In a study investigating long-term cardiovascular prognosis in Japanese patients with paroxysmal AF receiving AAD therapy using a composite outcome measure including sudden death, heart failure and thromboembolism, ${ }^{30}$ progression to chronic AF was specified as an independent predictor for cardiovascular events. These findings suggest that maintaining sinus rhythm is most important in patients with higher $\mathrm{CHADS}_{2}$ scores.

The results of the present study suggest that the $\mathrm{CHADS}_{2}$ score is not only beneficial in selecting an appropriate anticoagulation strategy to prevent ischemic stroke, ${ }^{31,32}$ but also useful in predicting the efficacy of AAD in preventing recurrent or chronic $\mathrm{AF}$ and thus ensuring optimal rhythm management.

\section{Study Limitations}

First, the present study was a retrospective observational study and there were some biases in the patient characteristics of the subgroups. Second, all participants underwent rhythm control therapy to maintain sinus rhythm, and the physicians selected AAD and upstream treatment using RAAS inhibitors and statins at their discretion. Although no significant difference in patients' characteristics were observed among the subgroups, we cannot rule out the possibility that some characteristics may affect the efficacy of AAD. ${ }^{33,34}$ Third, the study only involved patient with paroxysmal AF, and it is unclear whether the same findings would be obtained for patients with persistent AF. Finally, recurrent AF was diagnosed as ECG-documented AF. It has been reported that even patients with symptomatic paroxysmal AF are unaware of more than half of the episodes of tachycardia recorded during ambulatory 24-h ECG. ${ }^{35}$ In a study using the portable ECG monitoring device, Cardio-Phone, $30-70 \%$ of the episodes noticed as palpitation by patients with symptomatic AF were associated with sinus tachycardia or atrial extrasystole. ${ }^{36}$ There are a number of methodological limitations hindering physicians ability to know when AF actually recurs, and none of the currently available monitoring methods, other than device systems, can make a correct evaluation. Prospective multicenter comparative studies will be necessary to reevaluate the efficacy of AAD therapy in Japanese patients with paroxysmal AF. 


\section{Conclusions}

The $\mathrm{CHADS}_{2}$ score is a useful scheme for predicting the efficacy of $\mathrm{AAD}$ in preventing recurrent or chronic $\mathrm{AF}$ in Japanese patients with paroxysmal AF. The preventive efficacy of AAD therapy was lower in paroxysmal AF patients with higher $\mathrm{CHADS}_{2}$ scores.

\section{References}

1. Chugh SS, Blackshear JL, Shen WK, Hammill SC, Gersh BJ. Epidemiology and natural history of atrial fibrillation: Clinical implications. J Am Coll Cardiol 2001; 37: 371 - 378.

2. Ohsawa M, Okayama A, Sakata K, Kato K, Itai K, Onoda T, et al. Rapid increase in estimated number of persons with atrial fibrillation in Japan: An analysis from national surveys on cardiovascular disease in 1980, 1990 and 2000. J Epidemiol 2005; 15: 194-196.

3. Wolf PA, Abbott RD, Kannel WB. Atrial fibrillation: A major contributor to stroke in the elderly: The Framingham study. Arch Intern Med 1987; 147: 1561-1564.

4. Dries DL, Exner DV, Gersh BJ, Domanski MJ, Waclawiw MA, Stevenson LW. Atrial fibrillation is associated with an increased risk for mortality and heart failure progression in patients with asymptomatic and symptomatic left ventricular systolic dysfunction: A retrospective analysis of the SOLVD trials [Studies of Left Ventricular Dysfunction]. J Am Coll Cardiol 1998; 32: 695-703.

5. Lin HJ, Wolf PA, Kelly-Hayes M, Beiser AS, Kase CS, Benjamin EJ, et al. Stroke severity in atrial fibrillation: The Framingham Study. Stroke 1996; 27: 1760-1764.

6. Fuster V, Rydén LE, Cannom DS, Crijns HJ, Curtis AB, Ellenbogen $\mathrm{KA}$, et al. ACC/AHA/ESC guidelines for the management of patients with atrial fibrillation: Executive summary: A report of the American Collage/American Heart Association Task Force on Practice Guidelines and the European Society of Cardiology Committee for Practice Guidelines and Policy Conferences Developed in Collaboration With the European Heart Rhythm Association and the Heart Rhythm Society. Circulation 2006; 114: 700-752.

7. Sopher SM, Camm AJ. Atrial fibrillation: Maintenance of sinus rhythm versus rate control. Am J Cardiol 1996; 77: 24A-37A.

8. Ogihara T, Kikuchi K, Matsuoka H, Fujita T, Higaki J, Horiuchi M, et al. The Japanese Society of Hypertension Guidelines for the Management of Hypertension (JSH2009). Hypertens Res 2009; 32: 3 107.

9. Investigating Committee of Guideline for Diagnosis and Treatment of Hyperlipidemias. Guidelines for diagnosis and treatment of hyperlipidemia in adults. J Jpn Atheroscler Soc 1997; 25: 1-34.

10. Komatsu T, Tachibana H, Sato Y, Ozawa M, Nakamura M, Okumura $\mathrm{K}$. Efficacy of amiodarone for preventing the recurrence of symptomatic paroxysmal and persistent atrial fibrillation after cardioversion. Circ J 2007; 71: 46-51.

11. Kodama I, Aizawa Y, Inoue H, Ohe T, Ogawa S, Okumura K, et al. The guideline for drug treatment of arrhythmia (JCS 2004). Circ J 2004; 68(Supp IV): 981-1053 (in Japanese).

12. Hart RG, Pearce LA, McBride R, Rothbart RM, Asinger RW. Factors associated with ischemic stroke during aspirin therapy in atrial fibrillation: Analysis of 2012 participants in the SPAFI-III clinical trials: The Stroke Prevention in Atrial Fibrillation (SPAF) Investigators. Stroke 1999; 30: 1223-1229.

13. van Walraven C, Hart RG, Wells GA, Petersen P, Koudstaai RJ, Gullov AL, et al. A clinical prediction rule to identify patients with atrial fibrillation and a low risk for stroke while taking aspirin. Arch Intern Med 2003; 163: 936-943.

14. Komatsu T, Tachibana H, Sato Y, Ozawa M, Kunugida F, Nakamura $\mathrm{M}$, et al. Relationship between $\mathrm{CHADS}_{2}$ score and ischemic stroke during rhythm control therapy for paroxysmal atrial fibrillation. Int Heart J 2010; 51: 24-29.

15. Flaker GC, Blackshear JL, McBride R, Kronmal RA, Halperin JL, Hart RG. Antiarrhythmic drug therapy and cardiac mortality in atrial fibrillation: The Stroke Prevention in Atrial Fibrillation Investigators. J Am Coll Cardiol 1992; 20: 527-532.

16. Kato T, Yamashita T, Sagara K, Iinuma H, Fu L. Progressive nature of paroxysmal atrial fibrillation: Observation from a 14-year follow- up study. Circ J 2004; 68: 568-572.

17. Gold RL, Haffajee CI, Charos G, Sloan K, Baker S, Alpert JS. Amiodarone for refractory atrial fibrillation. Am J Cardiol 1986; 57: 124127.

18. Suttorp MJ, Kingma JH, Koomen EM, van't Hof A, Tijssen JGP, Lie KI. Recurrence of paroxysmal atrial fibrillation or flutter after successful cardioversion in patients with normal left ventricular function. Am J Cardiol 1993; 71: 710-713.

19. Skoularigis J, Röthlisberger C, Skudicky D, Essop MR, Wisenbaugh $\mathrm{T}$, Sareli P. Effectiveness of amiodarone and electrical cardioversion for chronic rheumatic atrial fibrillation after mitral valve surgery. Am J Cardiol 1993; 72: 423-427.

20. Flaker GC, Fletcher KA, Rothbart RM, Halperin JL, Hart RG. Clinical and echocardiographic features of intermittent atrial fibrillation that predict recurrent atrial fibrillation: Stroke Prevention in Atrial Fibrillation (SPAF) Investigators. Am J Cardiol 1995; 76: 355-358.

21. Clair WK, Wilkinson WE, McCarthy EA, Page RL, Pritchett EL. Spontaneous occurrence of symptomatic paroxysmal atrial fibrillation and paroxysmal supraventricular tachycardia in untreated patients. Circulation 1993; 87: 1114-1122.

22. Komatsu T, Yomogida K, Nakamura S, Suzuki O, Horiuchi D, Okumura K. Characteristics of the patients with paroxysmal atrial fibrillation and diabetes mellitus and long-term preventive efficacy according to antiarrhythmic drug therapy. Jpn J Electrocardiol 2005; 25: 173 - 180 (in Japanese).

23. Isomoto S, Fukatani M, Konoe A, Tanigawa M, Centurion OA, Seto $\mathrm{S}$, et al. The influence of advancing age on the electrophysiological changes of the atrial muscle induced by programmed atrial stimulation. Jpn Circ J 1992; 56: 776-782.

24. Davies MJ, Pomerance A. Pathology of atrial fibrillation in man. $\mathrm{Br}$ Heart J 1972; 34: 520-525.

25. Benjamin EJ, Levy D, Vaziri SM, D'Agostino RD, Belanger AJ, Wolf PA. Independent risk factors for atrial fibrillation in a population-based cohort: The Framingham Heart Study. JAMA 1994; 271: $840-844$.

26. Maisei WH, Stevenson LW. Atrial fibrillation in heart failure: Epidemiology, pathophysiology, and rationale for therapy. Am J Cardiol 2003; 91: 2D-8D.

27. Hamby RI, Zoneraich S, Sherman L. Diabetic cardiomyopathy. JAMA 1974; 229: $1749-1754$

28. Cameron NE, Cotter MA, Archibald V, Dines KC, Maxfield EK. Anti-oxidant and pro-oxidant effects on nerve conduction velocity, endoneural blood flow and oxygen tension in non-diabetic and streptozotocin-diabetic rats. Diabetologia 1994; 37: 449-459.

29. Corley SD, Epstein AE, DiMarco JP, Domanski MJ, Geller N, Greene HL, et al. Relationship between sinus rhythm, treatment, and survival in the Atrial Fibrillation Follow-up Investigation of Rhythm Management (AFFIRM) study. Circulation 2004; 109: 1509-1513.

30. Komatsu T, Tachibana H, Sato Y, Ozawa M, Kunugida F, Nakamura M. Clinical profiles, efficacy of antiarrhythmic drug therapy, and cardiovascular prognosis in patients with first-detected paroxysmal atrial fibrillation. Int Heart J 2011; 52: 32-38.

31. J-RHYTHM Registry Investigators. Determinants of warfarin use and international normalized ratio levels in atrial fibrillation patients in Japan: Subanalysis of the J-RHYTHM Registry. Circ J 2011; 75: $2357-2362$.

32. Okumura K, Komatsu T, Yamashita T, Okuyama Y, Harada M, Konta $\mathrm{Y}$, et al. Time in the therapeutic range during warfarin therapy in Japanese patients with non-valvular atrial fibrillation: A multicenter study of its status and influential factors. Circ J 2011; 75: $2087-$ 2094.

33. Endo A, Kohsaka S, Suzuki S, Atarashi H, Kamakura S, Sakurai M, et al. Impact of drug alternation to maintain rhythm control in paroxysmal atrial fibrillation: Subanalysis from J-RHYTHM study. Circ J 2010; 74: 870-875.

34. Aizawa Y, Kohsaka S, Suzuki S, Atarashi H, Kamakura S, Sakurai M, et al. Comparison of antiarrhythmic used in patients with atrial fibrillation: Subanalysis of J-RHYTHM Study. Circ J 2010; 74: 71-76.

35. Rho RW, Page RL. Asymptomatic atrial fibrillation. Progr Cardiovasc Dis 2005; 48: 79-87.

36. Fukuda Y, Akashi M, Noma S, Mitamura H, Ogawa S. Asymptomatic recurrence of atrial fibrillation: Cardiophone-guided management. Circ J 2003; 67(Suppl I): 310. 